\title{
Assessment of interactions between African swine fever virus, bushpigs (Potamochoerus larvatus), Ornithodoros ticks and domestic pigs in north- western Madagascar
}

\author{
J. Ravaomanana ${ }^{1}$, F. Jori' ${ }^{2,3}$, L. Vial ${ }^{3}$, R. Perez-Sanchez ${ }^{4}$, E. Blanco ${ }^{5}$, V. Michaud ${ }^{3}$ and F. Roger ${ }^{2}$ \\ FOFIFA, Malagasy Centre for Research in Agronomy, Antananarivo, Madagascar \\ CIRAD, AGIRs Unit, Montpellier, France \\ Mammal Research Institute, Department of Zoology, University of Pretoria, South Africa \\ UMR 15 ,CIRAD-INRA, CIRAD BIOS, Montpellier, France \\ Parasitology Laboratory, Instituto de Recursos Naturales y Agrobiologia de Salamanca, IRNASA/CSIC, Salamanca, Spain \\ CISA-INIA, Valdeolmos, Madrid, Spain
}

\section{Summary}

Since its introduction in Madagascar in 1998, African swine fever (ASF) has severely affected national pig production and persists as a common disease in that country. Two of its natural hosts in the African continent, the bushpig (Potamochoerus larvatus) and tick vectors of the Ornithodoros moubata complex, are reported in west and central regions of the island. However, their role in the maintenance and transmission of the virus has been insufficiently studied. In this work, we tried to assess their potential role in the epidemiology of the disease in Madagascar, by assessing the levels of interaction between (i) ASF virus (ASFV) and bushpigs and (ii) between soft ticks and domestic and wild suids in north-western Madagascar. Twenty-seven sera and 35 tissue samples from bushpigs were collected and analysed for the presence of anti-ASF antibodies and viral DNA. In addition, the sera from 27 bushpigs and 126 domestic pigs were analysed with an ELISA test for the detection of antibodies against salivary antigens from Ornithodoros ticks. No circulation of ASFV or anti-ASFV antibodies nor anti-tick antibodies were detected in bushpigs. However, seven of the domestic pig sera (5.6\% of the total sample population) were antibody positive for $O$. moubata antigens. The probability of freedom from ASFV in the bushpig population using Bayesian statistical methods ranged between $73 \%$ and $84 \%$. The probabilities of absence of anti-tick antibodies in domestic and wild pigs were estimated at $63 \%$ and $71 \%$, respectively. These preliminary results suggest that bushpigs are unlikely to play a significant role in the maintenance and transmission of ASFV in Madagascar. Nevertheless, further ASFV surveys are needed on that species to confirm this assumption. In addition, the presence of antibodies against $O$. moubata in domestic pigs suggests that soft ticks may be able to maintain ASFV within a domestic pig cycle in areas of Madagascar where they remain present.

\section{Keywords:}

African swine fever; ecology; Potamochoerus larvatus; Ornithodoros moubata complex; Madagascar

\section{Introduction}

African swine fever (ASF), caused by a DNA virus of the Family Asfarviridae, is one of the most serious diseases of domestic pigs in sub-Saharan African countries and is still threatening the pig population and the rural economy of other continents (Arias et al., 2002; Costard et al., 2009c). The virus is extremely contagious, and the lack of an efficient vaccine, together with the involvement of wild hosts able to maintain the virus in the environment, is considered the major constraint for control of the disease (Penrith et al., 2004; Rahimi et al., 2010). African swine fever has moved out of the African continent on an number of occasions (Costard et al., 2009c), being introduced in the Iberian Peninsula (Arias et al., 2002), Latin America, the Indian Ocean (Roger et al., 2001; Lubisi et al., 2009) and more recently spreading from the Caucasus region and Russia into Central Asia (Rowlands et al., 2009; Rahimi et al.,

Correspondence:

Ferran Jori. UPR AGIRs, CIRAD ES, Mammal Research Institute, Department of Zoology and Entomology, University of Pretoria, 0002 South Africa. Tel.: 01242020 16;

Fax: 01242025 34;

E-mail: ferran.jori@cirad.fr 
2010). In Europe, the disease has been maintained in the Island of Sardinia for many years through direct contact between domestic pigs and wild boars.

Wild suids - warthogs (Phacochoerus spp.) and bushpigs (Potamochoerus spp.) - and soft ticks of the genus Ornithodoros spp. are considered the most common natural hosts in the natural cycle of the disease described in Africa (Plowright et al., 1981). The specific relation between warthogs and soft ticks is extremely well described in the literature for eastern and southern Africa (Plowright et al., 1981; Thomson, 1985). Although there are some exceptions, high ASFV infection rates occur in most warthog populations examined in East and southern Africa reaching seroprevalences of $80 \%$ or higher. They get infected early in life, when bitten by $O$. moubata complex ticks living in the warthog burrows. Virus replicates in young warthogs causing viraemia which is sufficient to infect a proportion of ticks in the burrow and maintain the cycle. However, in other regions such as West Africa, important gaps of knowledge remain on the possible role of warthogs and soft ticks in the maintenance and transmission of the virus (Vial et al., 2007; Jori and Bastos, 2009).

As opposed to warthogs, the role played by bushpigs in the transmission of ASF is very poorly covered in the literature. Their susceptibility to ASFV was first recorded in 1921 (Montgomery, 1921) and in the 1960s. ASFV was isolated from several animals in East Africa (De Tray, 1963; Plowright et al., 1994). It is known that both species of Potamochoerus, the red river hog (P. porcus) and the bushpig (P. larvatus), can become infected with ASFV (Plowright et al., 1981; Luther et al., 2007) and become viraemic for several days without showing symptoms (Anderson et al., 1998). However, veterinary surveys of wild populations of Potamochoerus spp. are very scarce, and most reports document presence of the virus in lymphatic tissues. In fact, serological evidence of the virus in this species has not been demonstrated.

The presence of soft ticks from the O. moubata complex was reported on the western coast of Madagascar since the 18th century and confirmed by several authors in the first half of the 20th century (Le Gall, 1943). More recent investigations suggested their possible extinction from the northern part of the Island since the 1950s (Rodhain and Fontenille, 1989), but records of their presence remain in central parts of the country (Roger et al., 2001) and some evidence has been found recently of O. porcinus ticks being infected with ASFV (Ravaomanana et al., 2010).

One of the possible hypotheses explaining the persistence and endemicity of ASF in the Island is the potential role of wild hosts maintaining the virus in the environment. Despite the presence of $O$. moubata complex ticks and bushpigs in Madagascar, limited investigations have been undertaken to understand their contribution in the epidemiology of ASF and the interactions between these natural hosts and domestic pigs. The objective of this study was to fill that gap by (i) assessing the interactions between ASFV and bushpigs through the detection of ASFV antibodies and ASFV DNA in a sample of the bushpig population from the north-western region of Madagascar and by (ii) assessing the potential contacts between the argasid ticks and domestic and wild pigs through the detection of serum antibodies against $O$. moubata salivary antigens in the same sample of bushpigs $(«=27)$ and in a sample of domestic pigs $(«=126)$ taken from 67 farms and local abattoirs.

The results of those analyses were used to calculate the probability of freedom from disease in bushpigs and the probability of absence of contact between domestic and wild pigs and soft ticks using Bayesian statistical methods.

\section{Materials and Methods}

\section{Study site}

The study was carried out in Marovoay, a small riverine harbour of 65000 inhabitants, localized in north-western Madagascar, approximately $600 \mathrm{~km}$ from Antananarivo and $115 \mathrm{~km}$ from Mahajanga, the capital city in this region. The majority of the population $(60 \%)$ consists of agricultural farmers, while an additional $24 \%$ live from raising livestock. Traditional pig farming with local breeds is widespread in the region (Costard et al., 2009a). While in urban areas of Marovoay, $80 \%$ of pig farmers reported that their animals remain confined in pigsties all year long, in areas distant from the urban centre, free-ranging pigs are common and contacts between bushpigs and domestic pigs are often reported by farmers (C. Humbert, unpublished observations). This area has experienced several suspected outbreaks of ASF since the year 2000 and has had a number of laboratory confirmations based on ASFV isolation between 2002 and 2008 (V. Michaud, unpublished observations). Therefore, some of the potential agents for the development of a potential natural cycle of ASFV, such as the one described in the African continent, exist in this area of Madagascar, which is characterized by a hot and rainy climate. Average rainfall varies from 1000 with 1500 $\mathrm{mm}$ per year, and the normal temperature varies from 17 to $35^{\circ} \mathrm{C}$. The predominant natural vegetation is encompassed by $4680 \mathrm{~km}$ of dry semi-deciduous forest and bush savannah. Bushpigs (P. larvatus) in Madagascar are widespread in most forested areas of the island (Roger et al., 2001; Andrianjakarivelo et al., 2003). The 
Ankarafantsika National Park (ANP), which is only at $30 \mathrm{~km}$ from Maro-voay, encompasses a wide surface (1300 $\mathrm{km}^{2}$ ) of dry dense deciduous forest (see Fig. 1). This forest provides cover to an abundant population of bushpigs that are often hunted by forest gatherers (Garcia and Goodman, 2003) who trade with their meat in the markets of neighbouring towns. Bushpig meat is widely consumed and commercially traded in coastal regions of Madagascar, including the north-western coast (Andrianjakarivelo et al., 2003).

\section{Bushpig sampling design}

To plan sample collection, we calculated sample size and probabilities of the detection of ASFV in the available bushpig population with the use of Win Episcope 2.0 (Thrusfield et al., 2001). Very few data are available on bushpig population densities in Africa with no data at all for Madagascar. To estimate the total population of bushpigs in our study area, we hypothesized that densities could be similar to those described in the closest geographical areas of subtropical forest available in the literature. Therefore, we based our calculation on data from the east coast of South Africa, where bushpig ecology is well described. Therefore, we hypothesized that density in north-western Madagascar would also range from 0.35 to 0.5 individuals per $\mathrm{km}^{2}$ (Seydack, 1990). We further postulated that the total population of bushpigs in the forest study area $\left(4680 \mathrm{~km}^{2}\right)$ would be higher than 1500 individuals. Despite bushpigs being recognized as a potential reservoirs for ASFV, there are no data available on the prevalence of ASFV in this species. The only estimate in the literature suggests that the prevalence of ASFV in bushpig populations is probably 10 times lower than in warthogs.

As prevalence figures of ASFV in warthogs in southern and East Africa are usually described as being close to $90 \%$ (Plowright et al., 1981), we used a value of $8 \%$ as a plausible minimum prevalence in bushpigs. Considering this expected value, we calculated that a sample size of 35 animals would be sufficient to detect at least one infected animal in the estimated population with a $95 \%$ confidence interval, considering that the diagnostic tests were hypothetically perfect (100\% sensitive and specific).

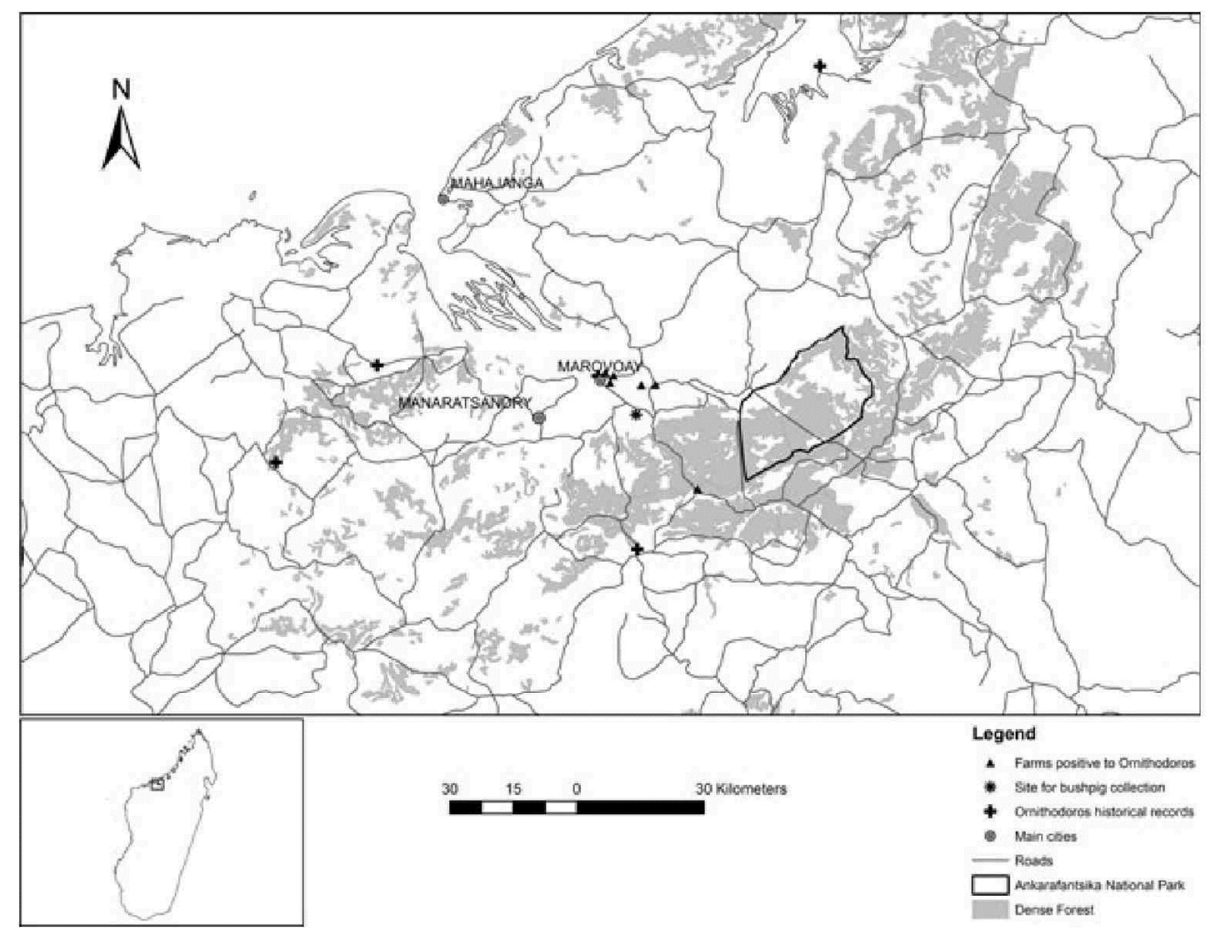

Fig. 1. Study site in Marovoay detailing the sampling site for bushpigs as well as historical soft tick collection points and location of farms with pigs positive to $O$. moubata antibodies. 


\section{Sampling strategy and collection}

\section{Bushpig samples}

With the collaboration of traditional hunters, 35 bushpigs were captured alive with traditional traps in the forested areas around Marovoay between June and September 2006 (see Fig. 1). While the animals were slaughtered to be traded in the local market, blood and tissue samples were collected.

Blood samples were kept at $+4^{\circ} \mathrm{C}$ during transport. Once in the laboratory, blood was centrifuged, the clot was removed and serum was stored at $-70^{\circ} \mathrm{C}$.

A 5-cm piece of spleen tissue was collected from every animal during carcass dressing off and placed in PBS with $100 / / \mathrm{g} / \mathrm{ml}$ of penicillin and streptomycin solution. Samples were stored at $+4^{\circ} \mathrm{C}$ until they could be stored in the laboratory at $-80^{\circ} \mathrm{C}$ to retain virus infectivity. A total of 35 tissue samples and 27 bushspig serum samples were then sent to reference laboratories in Europe to be tested for the presence of ASFV in tissues (CIRAD Virology Laboratory, Montpellier, France) and ASF antibodies in sera (CISA-INIA, Madrid, Spain), respectively.

\section{Domestic pig samples}

A batch of 126 domestic pig sera from the Marovoay area was chosen randomly from a larger sample of domestic pigs collected in a previous national prevalence study (Costard et al., 2009b). This sample represented a total of 38 animals collected at the local abattoir and 88 animals collected from 67 farms.

\section{Sample analysis}

\section{Serological screening of bushpig serum samples}

Different serological methods were used for the detection of antibodies against ASFV: The commercial kit p72 Blocking ELISA test (Ingezim PPA Compac 1.1.PPA K3 Elisa kit; Ingensasa, Madrid, Spain), described in the OIE Manual of Diagnostic Tests and Vaccines for Terrestrial Animals (OIE, 2008), was combined with other laboratorymade tests such as the Algenex rp30 ELISA and immunoblotting (Perez-Filgueira et al., 2006).

\section{ASFV DNA detection in bushpig tissue samples}

Spleen tissue samples were analysed for the presence of virus with conventional PCR (Polymerase Chain Reaction), a method internationally accepted for the detection of ASFV in the OIE Manual of Diagnostic Tests and Vaccines for Terrestrial Animals (OIE, 2008).

Two grams of spleen tissue was homogenized in $2 \mathrm{ml}$ Eagle minimum essential medium (EMEM) containing 50 $\mathrm{U} / \mathrm{ml}$ of penicillin, streptomycin and amphotericin B. The homogenate was then centrifuged, and the supernatant was recovered and preserved at $-80^{\circ} \mathrm{C}$ DNA (200 fil) was extracted and purified with a GFX Genomic Blood DNA purification kit (Amersham Biosciences) and preserved at $-20^{\circ} \mathrm{C}$.

One hundred nanograms of this DNA solution was used to amplify a DNA fragment of the B646L specific for the conserved regions of the VP72, following the protocol described by (Bastos et al., 2003).

Antibodies against tick saliva in bushpigs and domestic pigs' serum samples

Bushpig and domestic pig sera were tested for antibodies against O. moubata salivary antigens using an ELISA test developed in Spain for detecting Ornithodoros spp. In domestic pigs (Oleaga-Perez et al., 1994; Baranda et al., 1997).

\section{Statistical analysis}

Instead of classical frequentist statistics, we used Bayesian statistical methods which require starting with prior probability distributions which represent a robust procedure for incorporating information from previous studies: in our case prior values of prevalence, test specificity and sensitivity values. Posterior probabilities obtained after combining priors and observed data through Bayesian modelling can be used as easily interpretable alternatives to $\mathrm{P}$ values. The Bayesian approaches are well adapted to determine whether the prevalence or seroprevalence of an infectious disease in a sampled population exceeds a given cut-off value with small sample sizes (Branscum et al., 2006). If the estimated prevalence is below this cut-off value, the population could be considered as 'disease free'. Prior values of sensitivity and specificity were provided by experts who developed theses tests and are experienced in their routine laboratory application, and were also obtained from available literature. 
An additional assumption made was that the laboratory tests used in our study were designed and assessed for domestic pigs, and they were unlikely to perform accurately in bushpig samples. Thus, prior distributions reflecting this uncertainty about the performances (sensitivity and specificity) of the diagnostic tests used were incorporated into the Bayesian computation. We used binomial sampling to adjust for the fact that sample size was small compared to the total population $(n / N$ is $<0.1)$.

BetaBuster software, available at the UC Davis Diagnostic test web site http://www.epi.ucdavis.edu/diagnostictests/ betabuster.html ), allowed us to obtain probability distributions based on prior best guess values for sensitivity, specificity and prevalence. Distributions for the prevalence of ASFV DNA and ASF antibodies and anti-tick antibodies were considered to be uniform as we did not have any prior information about prevalence. The bushpig humoral response to tick bites from the O. moubata complex was considered to be the same than in domestic pigs - lasting for 4 months - (Baranda et al., 1997), although the level of uncertainty in this assumption was high.

The computation of posterior probability for disease freedom was performed by the software program Bayesfreecalc1 (Johnson et al., 2004), available at the UC Davis web site (http://www.epi.ucdavis.edu/diagnostictests/ betabuster.html).

The parameterization of the programme used a maximum population of 2000 individuals, a Monte Carlo size for binomial case of 20000 and a burn-in size for binomial case of 5000 .

We determined the posterior probability that a population of a given size with a given number of positive reactors (test positive individuals) out of a sample of size $\mathrm{n}$ truly exceeded some predetermined cut-off value. This cut-off value was established at $5 \%$ as a realistic compromise for assessing the level of freedom.

\section{Results}

\section{Laboratory analysis}

All samples from bushpigs (sera and spleen tissues) were found negative for both antibodies $(n=27)$ and virus $(n=$ 35 ). The 27 bushpig sera were also found negative for antibodies against $O$. moubata salivary antigens. Seven of 126 serum samples from domestic pigs (5.6\% of the sample), originating from seven different farms, showed a positive result for anti-tick antibodies.

\section{Probability of freedom of disease or absence of interactions}

Table 1 shows that the posterior probability for the sampled bushpig population being free of ASFV was estimated at $85 \%$. The probability for the same population of bushpigs being free of ASFV antibodies ranged between $73 \%$ and $75 \%$ depending on the diagnostic test used. The probability of the sampled animals being free of anti-tick antibodies (considering a prevalence cut-off at $5 \%$ ) was estimated to be $71 \%$ for bushpigs and at $61 \%$ for domestic pigs.

\section{Discussion}

Excluding the giant forest hog (Hylochoerus meinhertzhageni), for which contacts with domestic pigs are rare, the bushpig is probably the least studied from all the potential wild reservoirs of ASFV in Africa (Jori and Bastos, 2009). The absence of available data on its disease burden or ecology is unfortunate because they are often reported to interact with domestic pigs in many areas of their distribution range (Haresnape et al., 1985; Vercammen et al., 1993; Jori and Bastos, 2009) and are likely to share many common pathogens.

Except for the isolation of ASFV from several animals in East Africa (De Tray, 1963), the few recent studies on ASF prevalence in natural populations of Potamochoerus spp. are restricted to a single report of serological screening in 10 individuals sampled in Zimbabwe (Anderson et al., 1998) and another report of 11 individuals sampled (sera and spleen tissue) in Malawi (Haresnape et al., 1985). All the animals were negative.

Despite the small sample size in our study, it appears to be the largest survey on ASFV in wild bushpigs reported to date. Our bushpig samples tested negative for the presence of antibodies with both ELISA and immuno-blotting assays, and no virus was detected in spleen tissue by PCR, suggesting the absence of previous exposure and lack of current circulation of ASFV in the sampled population. The small sample size and the possibility that currently available diagnostic tests are not highly effective in this wild suid lead us to use of a Bayesian framework to quantify the uncertainty and the probability of freedom at the population scale. The results suggest that the 
probability of freedom of ASFV in the studied bushpig population ranges between $73 \%$ and $85 \%$, depending on the test used, and at the chosen cut-off of 5\% (Table 1). Anderson et al. (1998) reported that bushpigs were not able to become easily infected by horizontal transmission, when exposed to viraemic domestic pigs or bushpigs. However, bushpigs could become infected through occasional ingestion of infected domestic pigs or parts of their carcasses. This seems a plausible event in Marovoay where bushpigs and pigs are reported to share the same areas. Since 1998, several outbreaks of ASF in domestic pig farms have been suspected by farmers, and on at least in two occasions, the disease was confirmed by viral isolation, in 2002 and in 2008. Under these circumstances of recurrent viral circulation, common presence of bushpigs and possible contacts between bushpigs and free-ranging pigs, the likelihood of the bushpig population becoming infected with ASFV in our study area can be considered to be important.

Our results suggest that future attempts to detect ASFV in bushpigs in Madagascar - and this is also applicable for Africa - should be based on a larger sample size and on monitoring or surveillance systems (MOSS). Sampling should ideally consider different collection areas used by hunters and particularly those where possible contacts between free-ranging pigs and bushpigs could occur to maximize the probability of detection. Consequently, MOSS should be built up on risk assessment, structured as targeted repeated surveys or sentinel surveillance in the at-risk areas, and if at all possible, based on laboratory tests validated for the targeted species. Working with bushpigs in Africa is generally difficult because of their elusive nature and nocturnal habits (Haresnape et al., 1985). However, in Madagascar, those constraints can be addressed by collaborating with local stakeholders involved in the bushpig meat network (hunters, middlemen and market butchers), making the implementation of surveys at a larger scale easier than in other countries.

Despite the presence of ticks from the O. moubata complex being reported in the Marovoay region, there was no evidence of interactions between those and bush-pigs. This supports the hypothesis that unlike warthogs, bushpigs do not live in suitable habitats allowing the settlement of endophilous O. moubata complex ticks (Roger et al., 2001). Indeed, bushpigs' nests consist of temporary wet piles of grass in areas of dense vegetation (Vercam-men et al., 1993) which are unsuitable for O. moubata complex ticks (Penrith et al., 2004).

A few domestic pig samples were positive for anti-tick antibodies (7/126), according to the crude ELISA cut-off defined. However, no soft ticks' specimens were found in this area despite several in-depth field investigations in pig farms in Marovoay (Ravaomanana et al., 2010). Considering that the specificity of the test is close to $90 \%$ (Perez-Sanchez, R., unpublished observations), those positive samples could fall within the range of false-positive animals. Other alternative possibilities to explain those results are (i) that some of these samples are truly positive and that some domestic pigs have been bitten by soft tick less than 4 months ago, in our study area or (ii) that animals were bitten in other regions of the country, where O. moubata is still present, and were moved into Marovoay within the last 4 months. Indeed, recent findings have provided evidence of the existence ASFV-infected O. porcinus ticks in the Central Highlands of Madagascar (Ravaomanana et al., 2010); however, recent movement of pigs could not be conveniently investigated.

In this study, we used Bayesian statistics to estimate freedom of disease or absence of interactions between hosts. The advantages of using Bayesian framework are that (i) it can be used for small samples (Branscum et al., 2006), (ii) it allows great flexibility in managing statistical models both conceptually and computationally, (iii) it allows for the combination of field data and available scientific information, including uncertainty and variability, in a coherent approach and (iv) it allows direct probability understanding of outcome results, and therefore, practical and statistical significance can be readily evaluated by scientists and policymakers (University of California, 2006; Dohoo et al., 2009).

\section{Conclusions}

Our results suggest that prevalence of ASF virus in the sampled population of Madagascan bushpigs is low with a sporadic pattern or non-existent, supporting the hypothesis that bushpigs play an insignificant role in the maintenance and dissemination of ASF in Madagascar.

However, further studies with larger samples and/or MOSS, joining together ecological investigations and epidemiological surveys, remain necessary to confirm these findings. Equally, experimental infections of captive bush-pigs with ASFV, such as those developed in Zimbabwe at the end of 1990s (Anderson et al., 1998; Oura et al., 1998), should be replicated in Madagascar to elucidate the susceptibility of the Madagascar variety of P. larvatus to local ASF circulating viral strains.

No evidence of interactions between soft ticks and bushpigs could be found in our study. However, the occurrence of a limited number of positive domestic pigs to O. moubata complex antibodies raises the hypothesis that 
Table 1. Estimated probability that bushpigs are free of ASFV DNA, ASF antibodies and anti-tick antibodies given different prevalence cut-offs. The prior prevalence is Beta (1,1)

\begin{tabular}{|c|c|c|c|c|c|c|c|c|c|c|c|c|c|}
\hline \multirow{2}{*}{$\begin{array}{l}\text { TESTS } \\
\text { Bushpig }\end{array}$} & \multirow[t]{2}{*}{ Performances/confidence } & \multirow[t]{2}{*}{$\begin{array}{l}\text { Confidence } \\
\%\end{array}$} & \multirow[t]{2}{*}{$\begin{array}{l}\text { Se } \\
\text { mode } \\
(\%)\end{array}$} & \multirow[t]{2}{*}{$\begin{array}{l}\text { Se } \\
\text { percentile } \\
(\%)\end{array}$} & \multicolumn{2}{|c|}{$\begin{array}{l}\text { Beta } \\
\text { distribution } \\
(a, b) \text { for Se }\end{array}$} & \multirow[t]{2}{*}{$\begin{array}{l}\text { Sp } \\
\text { mode } \\
(\%)\end{array}$} & \multirow[t]{2}{*}{$\begin{array}{l}\text { Sp } \\
\text { percentile } \\
(\%)\end{array}$} & \multicolumn{2}{|c|}{$\begin{array}{l}\text { Beta } \\
\text { distribution } \\
(a, b) \text { for } S p\end{array}$} & \multirow[t]{2}{*}{$\begin{array}{l}\text { Total } \\
\text { number of } \\
\text { samples }\end{array}$} & \multirow[t]{2}{*}{$\begin{array}{l}\text { Number } \\
\text { Positive } \\
\text { samples }\end{array}$} & \multirow[t]{2}{*}{$\begin{array}{l}\text { P freedom } \\
\text { (cut-off 5\%) }\end{array}$} \\
\hline & & & & & & & & & & & & & \\
\hline ASFV PCR & High/high & 95 & 99 & 95 & 88.280 & 1.882 & 99 & 95 & 88.280 & 1.882 & 35 & 0 & 0.84 \\
\hline bELISA ASF Ab (INGENASA) & Moderate/moderate & 80 & 95 & 90 & 40.578 & 3.083 & 95 & 90 & 40.578 & 3.083 & 27 & 0 & 0.73 \\
\hline p30 ELISA ASF Ab & Moderate/moderate & 80 & 95 & 90 & 40.578 & 3.083 & 95 & 90 & 40.578 & 3.083 & 27 & 0 & 0.73 \\
\hline Western Blot ASF Ab & High/high & 95 & 99 & 95 & 88.280 & 1.882 & 99 & 95 & 88.280 & 1.882 & 27 & 0 & 0.75 \\
\hline ELISA Ornithodoros moubata Ab & $\begin{array}{l}\text { Moderate (Se) - low } \\
\text { (Sp)/low }\end{array}$ & 50 & 90 & 80 & 4.727 & 1.414 & 80 & 70 & 3.212 & 1.553 & 27 & 0 & 0.71 \\
\hline \multicolumn{14}{|l|}{ Domestic pig } \\
\hline ELISA O. moubata $A b$ & $\begin{array}{l}\text { Moderate (Se) - low } \\
(\mathrm{Sp}) \text { /low }\end{array}$ & 50 & 90 & 80 & 4.727 & 1.414 & 80 & 70 & 3.212 & 1.553 & 118 & 7 & 0.63 \\
\hline
\end{tabular}

ASF, African swine fever; ASFV, ASF virus; Ab, Antibodies; Se, Sensitivity; Sp, Specificity. 
occasional contacts between domestic pigs and soft ticks are possible and that the arthropods could contribute to ASFV maintenance in the environment, in areas where the tick remains present.

\section{Acknowledgements}

The study was carried out from 2006 to 2008 within the framework of the research project 'Diagnosis, epidemiology and control of African swine fever virus' funded by the Wellcome Trust ( $\mathrm{N}^{\circ} 210183$. 183, AHDW/03/04). The work at CISA-INIA was supported by CYCIT (AGL07-66441-CO3-O2) and CSD (00C-06-02320). We also express our gratitude to the Veterinary Services of Madagascar, the Maison du Petit Elevage and Dr Abel Andriatsimahavandy from the University of Antananarivo for supporting this work. We also thank Prof. Antonio Encinas Grandes from the University of Salamanca for his availability and cooperation regarding the salivary gland ELISA test and Dr Armanda Bastos for reviewing the manuscript.

\section{References}

Anderson, E. C, G. H. Hutchings, N. Mukarati, and P. J. Wilkinson, 1998: African swine fever virus infection of the bushpig (Potamochoerus porcus) and its significance in the epidemiology of the disease. Vet. Microbiol. 62, 1-15.

Andrianjakarivelo, V., S. Goodman, and J. Benstead, 2003: Artiodactyla: Potamochoerus larvatus, Bush Pig, Lambo, Lambodia, Lamboala, Antsanga. In: Goodman, S., and J. Benstead (eds), The Natural History of Madagascar, pp. 1365-1367. The University of Chicago Press, Chicago.

Arias, M. L., J. M. Sanchez-Vizcaino, A. Morilla, K. J. Yoon, and J. F. Zimmermann, 2002: African swine fever. In: Morilla, A., K. J. Yoon, and J. F. Zimmermann (eds), Trends in Emerging Viral Infections of Swine, pp. 119-139. Iowa State University Press, Ames.

Baranda, J. A., R. Perez-Sanchez, A. Oleaga-Perez, and A. Encinas Grandes, 1997: Antigens of interest for the diagnosis of parasitism in pigs by Ornithodoros erraticus and Ornithodoros moubata. J. Parasitol. 83, 831-835.

Bastos, A. D. S., M. L. Penrith, C. Crucie're, J. L. Edritch, G. H. Hutchings, F. Roger, E. Couacy-Hymann, and G. R. Thomson, 2003: Genotyping field strains of African swine fever virus by partial p72 gene characterisation. Arch. Virol. 148, 693-706.

Branscum, A. J., W. O. Johnson, and I. A. Gardner, 2006: Sample calculations for disease freedom and prevalence estimation surveys. Stat. Med. 25, 2658-2674.

Costard, S., V. Porphyre, S. Messad, S. Rakotondrahanta, H. Vidon, F. Roger, and D. U. Pfeiffer, 2009a: Multivariate analysis of management and biosecurity practices in smallholder pig farms in Madagascar. Prev. Vet. Med. 92, 199- 209.

Costard, S., T. Radriamparany, C. Humbert, S. Franco, H. Ras-amoelina, S. Rakotodrahanta, E. Albina, F. Roger, and D. U. Pfeiffer, 2009b: Estimating the prevalence of African swine fever in Madagascar. 12th International Conference of veterinary Epidemiology and Economics (ISVEE). Durban, South Africa.

Costard, S., B. Wieland, W. F. Jori, R. Rowlands, W. Vosloo, F. Roger, D. U. Pfeiffer, and L. Dixon, 2009c: African swine fever: How can global spread be prevented? Philos. Trans. R. Soc. Lond., B, Biol. Sci. 364, 2683-2696.

De Tray, D. E., 1963: African swine fever. Adv. Vet. Sci. Comp. Med. 19, 299-333.

Dohoo, I., W. Martin, and H. Stryhn, 2009: Veterinary Epidemiologic Research, 2nd edn. University Of Prince Edward Island Press, Charlottetown.

Garcia, G., and S. M. Goodman, 2003: Hunting of protected animals in the Parc National d'Ankarafantsika, northwestern Madagascar. Oryx 37, 115-118.

Haresnape, J. M., S. A. Lungu, and F. D. Mamu, 1985: A four year survey of African swine fever in Malawi. J. Hyg. (Lond) 95, 309-323.

Johnson, W. O., C. L. Su, I. A. Gardner, and R. Christensen, 2004: Sample size calculations for surveys to substantiate freedom of populations from infectious agents. Biometrics 60, 165-171.

Jori, F., and A. D. S. Bastos, 2009: Role of wild suids in the epidemiology of African swine fever. EcoHealth, 6, 296310.

Le Gall, R., 1943: Vue d'ensemble sur les maladies pestilenti-elles, ende'mo-e'pide'miques, transmissibles et sociales a Madagascar entre 1936 et 1940. Bull. Off. int. Hyg. publ. 37, 417-450.

Lubisi, B. A., R. M. Dwarka, D. Meenowa, and R. Jaumally, 2009: An investigation into the first outbreak of African swine fever in the Republic of Mauritius. Transbound Emerg. Dis. 56, 178-188.

Luther, N. J., K. A. Majiyagbe, D. Shamaki, L. H. Lombin, J. F. Antiagbong, Y. Bitrus, and O. Owolodun, 2007: Detection of African swine fever virus genomic DNA in a Nigerian red river hog (Potamochoerus porcus). Vet. Rec. $160,58-59$. 
Montgomery, R. E., 1921: On a form of swine fever occurring in British East Africa (Kenya Colony). J. Comp. Pathol. $34,243-262$.

OIE, 2008: African Swine Fever. Available at: http://www.oie.int/eng/normes/mmanual/2008/pdf/2.08.01_ASF.pdf. 2010).

Oleaga-Perez, A., R. Perez-Sanchez, A. Astigarraga, and A. Encinas Grandes, 1994: Detection of pig farms with Ornithodoros erraticus by pig serology. Elimination of nonspecific reactions by carbohydrate epitopes of salivary antigens. Vet. Parasitol. 52, 97-111.

Oura, C. A., P. P. Powell, E. Anderson, and R. M. Parkhouse, 1998: The pathogenesis of African swine fever in the resistant bushpig. J. Gen. Virol. 79, 1439-1443.

Penrith, M. L., G. R. Thomson, and A. D. S. Bastos, 2004: African swine fever. In: Coetzer, J. A. W., and R. C. Tustin (eds), Infectious Diseases of Livestock with Special Reference to Southern Africa, pp. 1088-1119. Oxford University Press, Cape Town.

Perez-Filgueira, D. M., F. Gonzalez-Camacho, C. Gallardo, P. Resino-Talavan, E. Blanco, E. Gomez-Casado, C. Alonso, and J. M. Escribano, 2006: Optimization and Validation of Recombinant Serological Tests for African Swine Fever Diagnosis Based on Detection of the p30 Protein Produced in Trichoplusia ni Larvae. J. Clin. Microbiol. 44, 3114-3121.

Plowright, W. 1981: African swine fever. In: Davis, J. W., L. H. Karstad, and D. O. Trainer (ed), Infectious Diseases of Wild Mammals, pp. 178-190. Iowa University Press, Iowa.

Plowright, W., G. R. Thomson, and J. A. Neser, 1994: African swine fever. In: Coetzer, J. A. W., G. R. Thomson, and R. C. Tustin (eds), Infectious Diseases of livestock with special reference to Southern Africa, pp. 567-599. Oxford University Press, Cape Town.

Rahimi, P., A. Sohrabi, J. Ashrafihelan, R. Edalat, M. Alamdari, and M. Masoudi, 2010: Emergence of African swine fever virus, northwestern Iran. Available at: http://www.cdc.gov/EID/content/16/12/1946.htm (accessed December $16,2010)$.

Ravaomanana, J., V. Michaud, F. Jori, A. Andriatsimahavandy, F. Roger, E. Albina, and L. Vial, 2010: First detection of African Swine Fever Virus in Ornithodoros porcinus in Madagascar and new insights into tick distribution and taxonomy. Parasit. Vectors 3, 115.

Rodhain, F., and D. Fontenille, 1989: La fie'vre re'currente a' tiques malgache, une affection e'radique'e? Bull. Soc. Pathol. Exot. 82, 192-198.

Roger, F., J. Ratovonjato, P. Vola, and G. Uilenber, 2001: Ornithodoros porcinus ticks, bushpigs, and African swine fever in Madagascar. Exp. Appl. Acarol. 25, 263-269.

Rowlands, R. J., V. Michaud, L. Heath, G. H. Hutchings, C. A. Oura, W. Vosloo, R. Dwarka, T. Onashivili, E. Albina, and L. Dixon, 2009: African Swine Fever Virus Isolate, Georgia, 2007. Emerg. Infect. Dis. 14, $1870-1874$.

Seydack, A.H.W., 1990: The ecology of the bushpig (Potamo-choerus porcus Linn. 1758) in the Cape Province. South Africa. PhD Dissertation, University of Stellenbosch, Stellenbosch, South Africa, 728 pp.

Thomson, G. R., 1985: The epidemiology of African swine fever: the role of free living hosts in Africa. Onderstepoort J. Vet. Res. 52, 201-209.

Thrusfield, M., C. Ortega, I. de Blas, J. P. Noordhuizen, and K. Frankena, 2001: Win Episcope 2.0: improved epidemiological software for veterinary medicine. Vet. Rec. 148, 567-572.

University of California, Davis, 2006: BEST-Bayesian Epidemiologic Screening Techniques. Sotware Modules. BetaBuster. Available at: http://www.epi.ucdavis.edu/diagnostictests/ betabuster.html (accessed 30 January 2011).

Vercammen, P., A. H. W. Seydack, and W. L. B. Oliver, 1993: Chapter 4.4.: The Bush Pigs (Potamochoerus porcus and P. larvatus). In: Oliver, W. L. B. (ed.), Pigs, Peccaries and Hippos Status Survey and Action Plan, pp. 93-101. IUCN/ SSC, Gland, Switzerland.

Vial, L., B. Wieland, F. Jori, E. Etter, L. Dixon, and F. Roger, 2007: African swine fever virus DNA in soft ticks, Senegal. Emerg. Infect. Dis. 13, 1928-1931. 